\title{
14 Al otro lado. Los sistemas productivos de las literaturas locales (latinoamericanas)
}

Cerré el capítulo I con la sugerencia implícita de distinguir entre "literatura latinoamericana” y literatura latinoamericana, sin comillas. Si la primera es la que se produce para el mundo, según los lineamientos que traté de conceptualizar en el capítulo II y de un modo total o parcialmente desterritorializado en lo que refiere a los diferentes momentos de la cadena de ensamblaje, el segundo término intentaría retener un algo contenido en las producciones que se resuelven más estrictamente dentro de los marcos geográficos e idiosincráticos del subcontinente y que, solo en ocasiones, sin mayor premeditación, los desbordan. Este recorte, antes que suponer que existe una literatura latinoamericana “auténtica” definida sobre la base de atributos esencialistas o marcas "típicas", lo que estaría proponiendo es considerar que las condiciones materiales de producción en el nivel mundial y en el más específico de América Latina no son las mismas, esto es, que las condiciones bajo las cuales se elabora la literatura en las configuraciones locales de una región ciertamente con desventajas materiales relativas estarían afectando, y distinguiendo, los objetos producidos. Se trata, dicho en breve, de que las literaturas latinoamericanas, como sucede, aunque sea de otro modo, con la literatura latinoamericana mundial, poseerían inscripciones que dan cuenta de y remiten a las condiciones de producción particulares en las que emergen.

Escribe Nora Catelli que

\footnotetext{
Cuanto más internacional y controlada por los grandes grupos es la circulación de los autores, más se ve que en las distintas capitales sigue existiendo una visible impronta nacional, que nunca coincide del todo con la jerarquización que los polos exteriores atribuyen a sus autores: algunos son más aceptables, legibles, adoptables que otros. (7)
}

Este capítulo está dedicado a las literaturas locales, es decir, a las producciones que, en el marco de la actual fase de la globalización, por alguna razón o por otra, no se insertan -no lo logran, no lo pretenden- en dinámicas de circulación internacional o, valga el término de Catelli, a las que resultan menos “adoptables" por los polos exteriores. Este fenómeno de las literaturas relativamente dependientes de contextos específicos es concomitante y debe ser leído en paralelo al de la literatura latinoamericana mundial: constituiría -y esto atañe a los estudios literarios del Norte- su lado reprimido, silenciado. Como sugiere Catelli, la expansión de los grupos polirrubros de la industria cultural internacional trae aparejado un desarrollo de formas productivas marcadamente territorializadas, pero, si bien tal vez sería constatable el refuerzo de las literaturas

Ә Open Access. (c) 2019 Jorge J. Locane, published by De Gruyter. (c))BY-NC-ND This work is licensed under the Creative Commons Attribution-NonCommercial-NoDerivatives 4.0 License. 
nacionales que ella señala, personalmente voy a preferir el término literaturas locales porque -como voy a mostrar- existen contadas evidencias de que, para muchos sistemas productivos más localizados, el marco nacional ha dejado de ser una referencia: tanto porque hay literaturas que no circulan más allá de ciertos dominios locales no nacionales, así como porque la tradición literaria nacional, con sus memorias, ademanes y actos reflejo, no opera ni como archivo ni como retícula de deseo.

Las literaturas locales son, como ya adelanté en el capítulo I, producciones que no trascienden más allá de circunscripciones geográficas específicas; no van ante todo porque no pueden pero también, en casos, porque no quieren ${ }^{1}$ - en busca de lectores "extranjeros”, por lo que reclaman que la mirada analítica vaya a su encuentro. Las literaturas locales emergen de sistemas productivos que se diferencian en muchos aspectos del de la industria cultural transnacional ya analizado en el capítulo II: dependen de circuitos editoriales con baja proyección de ventas y escasa cobertura territorial. No obstante esta delimitación, anoto desde ya que hay una zona -y esta sería tal vez la función del dominio más estrictamente nacional- donde ambos sistemas productivos se encuentran y entrelazan. Si en el dominio transnacional la edición artesanal y autogestionada se halla -y no podría ser de otro modo- completamente excluida, en los circuitos nacionales, donde esta puede tener cierta presencia, la industria transnacional disfruta de un importante poder de penetración. Sucede que los grandes grupos transnacionales segmentan su oferta de acuerdo con demandas nacionales y adquieren, así, apariencias localizadas: el catálogo de Random House Mondadori en México se diferencia, por lo tanto, del de Random House Mondadori en Argentina. Solo el catálogo centralizado, el que se establece y gestiona directamente en la metrópoli, posee carácter “global”. De este modo, los grupos transnacionales, al realizarse de modo específico en el nivel nacional, logran también intervenir en las dinámicas locales. De acá que ciertas producciones del nivel local convivan y compartan espacios -librerías, ferias, suplementos culturales - con las que ofrece la industria transnacional. De acá también que exista un itinerario modelo para un/a escritor/a latinoamericano/a con expectativas de proyección internacional: del circuito local y autogestionado al catálogo nacional de una editorial transnacional y de ahí al centralizado, por regla general, en España. El circuito que va del orden local al nacional, o conviene desde ya acotar- una parte de él, funciona, así, como laboratorio donde

1 Mientras que Economías de guerra se presenta como "una editorial local”, la española, con base en Logroño, Pepitas de calabaza lo hace como "Un editorial con menos proyección que un cinexín". 
los escritores emergentes hacen su prueba de fuego y, una vez que dan evidencias de sustentabilidad, cuando ya no se presentan como una incertidumbre total, son asimilados y capitalizados por la industria transnacional, primero, en su realización nacional -Iosi Havilio, por ejemplo, después de publicar con cierto éxito Opendoor (2006) en la editorial Entropía pasa a Random House Mondadori de Argentina; Diego Zúñiga publica Camanchaca en La calabaza del diablo (2009) y Literatura Mondadori de Chile la reedita en el 2013² - y, luego, internacional -Julián Herbert publicó La casa del dolor ajeno en 2015 en Literatura Random House México y en 2016 en la casa matriz en Barcelona-. El dominio nacional sería, por lo tanto, una zona de potencial intersección y negociación entre los circuitos locales más circunscriptos y el transnacional.

Estos entrelazamientos y transiciones introducen, sin duda, ciertas complejidades en el modelo que estoy proponiendo conceptualizar. Estos cruces, que incluyen, por ejemplo, la posibilidad de que un editor alternativo publique, como escritor, en uno de los dos grandes grupos -valga el caso de Luigi Amara de Tumbona-, no deberían obturar, no obstante, la necesidad de evaluar como claramente diferenciadas las condiciones materiales y también, al menos parcialmente, las lógicas de gestión que dominan en cada uno de los dos escenarios. Más aún si el foco se concentra en la zona que, para los fines de este estudio, más interesa: en los sistemas productivos locales -es decir, en los que presentan, incluso, escasa o nula proyección nacional- que abiertamente rechazan -en casos porque no están en condiciones de hacerlo- compartir un programa procedimental e ideológico con la industria editorial más o menos formal, más o menos "profesional".

En lo que sigue propongo examinar algunas característica particulares de los sistemas productivos de las literaturas locales latinoamericanas. A diferencia de lo que sucede en la escala de la literatura mundial, en los circuitos locales un sujeto o un reducido colectivo puede -en el sentido de que la posibilidad existe- concentrar varias o todas las tareas profesionales. ${ }^{3}$ Así, la cadena de

2 Para un análisis del caso de Diego Zúñiga y otros escritores como Selva Almada, véase el artículo ya mencionado de Ana Gallego Cuiñas “Las narrativas del siglo XXI...”, donde sostiene que "ciertas editoriales independientes funcionan como mediadoras de la tasación del valor de la narrativa 'latinoamericana' en el sistema literario mundial. Apuestan por autores noveles y estéticas alternativas, de las que luego se apropian los grandes conglomerados para insertarlos en circuitos (trans)nacionales que potencian su visibilidad y reconocimiento" (9).

3 Precisamente Luigi Amara, en tanto vocero del colectivo mexicano Tumbona, asegura que "La editorial [Tumbona] no está compartimentada en una cadena de producción; se busca que el libro se cree, desde su conceptualización hasta su difusión y distribución, como un mismo proceso; no se delega a otros el trabajo sino que se hace en colaboración con el autor; no es una cuestión de encargo" (69). 
mediaciones, que en el nivel internacional resulta insoslayable, se comprime hasta permitir, al margen de la sensible reducción de costos, que incluso una única persona asuma todas las etapas del proceso productivo: desde la elaboración de contenido, la escritura, hasta la distribución e incluso la entrega en mano al sujeto consumidor. Cabe aclarar que este proceso, cuando efectivamente se realiza de esta última manera, no estaría, no obstante, convirtiendo a la literatura en un fenómeno de elaboración individual, atribuible a una entidad individual igual a sí misma y no sujeta al entorno social en el que se ubica, sino que, simplemente, estaría dando lugar a un producto menos mediado, más controlado.

Esto, que -como señalé- existe antes como posibilidad que como mandato ineludible, responde a circunstancias materiales concretas vinculadas a la precariedad constitutiva de los territorios donde el capitalismo global se sobreimprime sobre realidades marcadas por experiencias de expropiación (neo)colonial y que, por lo tanto, fracasa sistemáticamente como solución emancipatoria capaz de generar igualdad y bienestar social. De acá que la crisis institucional y el estallido social del 2001 en Argentina sea un momento clave, que también puso en evidencia los límites y aporías de la concentración editorial, para el desarrollo de la edición local y autogestionada en todo el subcontinente. La red de editoriales cartoneras es, acaso, la expresión más cabal del fenómeno que quiero representar, pero, desde ya, no la única. Repasemos algunas experiencias y testimonios.

Belleza y felicidad, que vale como iniciativa pionera y de referencia, ${ }^{4}$ es un espacio creativo y de activismo conducido por Fernanda Laguna, Cecilia Pavón y Gabriela Bejerman desde 1999, cuando el derrumbe del experimento neoliberal argentino de los años 90 ya estaba anunciado. Desde 2001 -aunque hay algunos registros aislados previos- publican libros en fotocopias, abrochados, que circulan, sin ISBN, fuera del circuito comercial (Fig. 6).

En el autorretrato de la editorial incluido en el libro Encuentro chileno de editoriales independientes (2012), se lee:

Nuestra idea fue la de hacer libros bien breves. En principio, diría que esto respondía a una cuestión económica: cuando empezamos a publicar, en el 2001, era un momento en donde nadie tenía un peso. [...] Si vos ves la literatura de cordel, también ahí hay una urgencia de expresión. Cuando hay una urgencia de expresión, siempre surgen cosas nuevas. Y cuando uno hace algo nuevo, y tiene una urgencia, por lo general, tiene que hacerlo por sí mismo, como un grafitero: inventar un lenguaje para poder expresar algo.

(“Belleza y felicidad” 23-24)

4 Para mayores datos al respecto, véanse los estudios de Moscardi La máquina..., Palmeiro y Francica. 


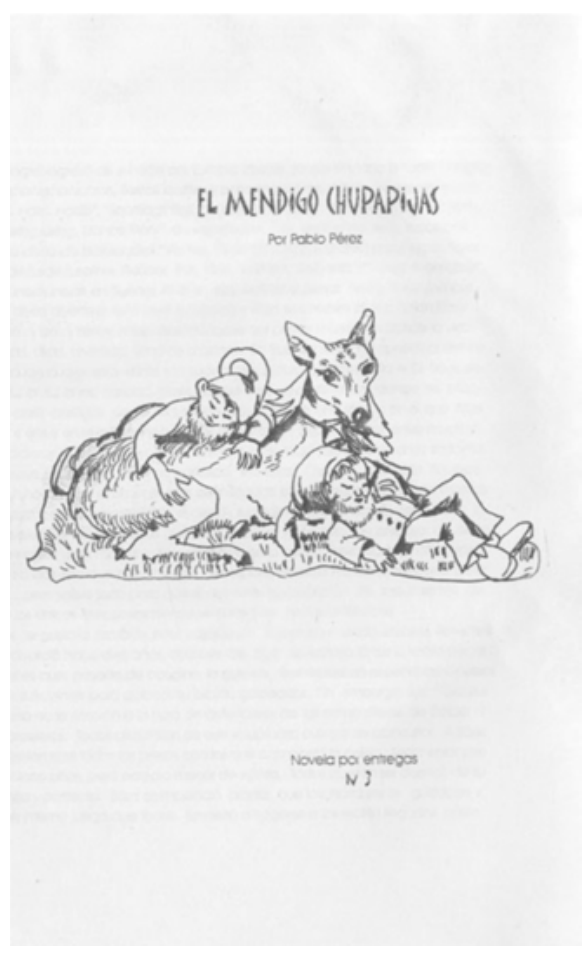

Fig. 6: Portada de la tercera entrega de El mendigo chupapijas (1999-2000), primera publicación de Belleza y felicidad (@ Belleza y felicidad 2000).

La coyuntura crítica de Argentina hacia fines de los 90 y principios de los años 00 fue, por lo tanto, un aliciente importante para que se desencadenara una suerte de toma de conciencia de que la solución a las necesidades de expresión y publicación no iba a provenir de la industria cultural establecida y que, por lo tanto, era necesario desarrollar plataformas propias, alternativas y autogestionadas. Pero, como se puede extraer de la cita, las condiciones de precariedad relativa atraviesan la historia del subcontinente, de modo que también resulta posible establecer un vínculo con la literatura de cordel, es decir, con otro territorio y otro momento histórico. ${ }^{5}$ Esas condiciones, además e independientemente de

5 De hecho, en uno de sus estudios sobre folletos y cordel, Márcia Abreu escribe que "Se há identidades materiais entre folhetos e cordéis é provavelmente porque, diante de dificuldades sociais e econômicas semelhantes, encontram-se soluções semelhantes. Publicar pequenas brochuras, em papel barato, parece ser a melhor solução quando não se possuem recursos para edição de livros compostos segundo o padrão da elite ou quando se quer atingir um público 
cuál sea el contexto específico, van a alentar -si no obligar a- la experimentación con recursos y formatos. Más allá del estallido del 2001 y más allá de Argentina, las condiciones de precariedad relativa son, en América Latina, similares en sus aspectos básicos. La concentración y con ello las restricciones en el acceso al sector editorial nacional de tamaño medio, a su vez, es un fenómeno que llegó, para quedarse, en los años 90 a todo el subcontinente. Esto ha favorecido que, en todo el territorio y desde ese momento en adelante, las escritoras y escritores hayan -como Laguna, Bejerman y Pavón- devenido, ya sea como parte de colectivos, ya sea como sujetos individuales, editores. En referencia al caso chileno, Rafael Farías Becerra, quien ubica el despegue de la edición autogestionada de ese país en los años 90, anota que

si dentro de esta gran proliferación de editoriales independientes lo que aparece con mayor énfasis es la política colectiva del "editor", lo que no puede pasarse por alto es que la mayoría de estas editoriales está conformada por "escritores”. Han sido en gran parte poetas, narradores, ensayistas, etc., quienes han decidido producir sus propias obras y espacios de producción y difusión haciendo frente al desinterés de las grandes industrias editoriales. Esto último, no sólo las ha llevado a colectivizar sus esfuerzos para tener una mayor influencia y visibilidad dentro de la sociedad, sino que les ha dado la posibilidad de aventurarse hacia nuevas formas de sensibilidad. (5)

Así, la carencia de recursos crónica, sumada a la concentración y el cambio de lógica en la industria editorial tradicional, ha favorecido tanto que los escritores activaran mecanismos para producir canales de difusión autogestionados así como el desarrollo de políticas editoriales alternativas e incluso abiertamente disidentes. Un caso particular, en el que un sujeto asume todas las funciones de la cadena productiva, es el de Eric Schierloh y su editorial "artesanal” y "hogareña” Barba de abejas, de City Bell, Provincia de Buenos Aires, donde desde fines del 2010 aparecen libros confeccionados completamente a mano en tiradas iniciales de cincuenta ejemplares numerados. Además de poeta, Schierloh es traductor del inglés. Sobre él, Matías Moscardi escribe: "El Gran Traductor Argentino se llama Eric Schierloh -conocido como Billy, el Apicultor- y editor del sello Barba de Abejas. El rótulo de 'editor' le queda particularmente chico: Schierloh es impresor, ilustrador, diseñador y encuadernador de los libros de su editorial” (“El traductor...”). Y, luego, agrega: "No se trata simplemente de hacer un producto autosustentable y mucho menos rentable, sino de tener una política editorial que proteja el aura de los objetos artísticos que salen de la mente del Gran

que não tem condições de adquirir ou compreender esses livros. A ideia de produzir folhetinhos baratos é boa e por isso mesmo não ocorreu poucas vezes: há publicações desse tipo em várias partes do mundo" (134). 
Traductor. Por eso, los libros de Barba de Abejas no podrían ser absorbidos por las grandes lógicas del mercado”. Se advierte, así, que, por razones que tienen que ver con la lógica productiva y por el tipo de objetos “anómalos”, a veces similares a libros convencionales, a veces completamente diferentes, estos sellos-proyectos mínimos, ya sea conducidos por pequeños colectivos -como en el caso de las cartoneras, de Belleza y felicidad o de Tumbona de México- o por un sujeto individual, conforman un circuito paralelo, tendiente a desmarcarse del que aparece dominado por las corporaciones transnacionales, y a configurar un sistema cerrado sobre sí mismo, con unas contadas librerías especializadas y ferias alternativas que le sirven de infraestructura para la llegada a los lectores: “decidimos”, -dice, por ejemplo, Julián Bejarano, de Gigante, “vender nosotros mismos nuestro producto a través de internet y en ferias y en lecturas y eventos a los que nos invitan. Nuestra idea no es hacer algo masivo ni que esto nos salve para que dejemos de trabajar y vivir de hacer lo que nos gusta” (Porrúa 80).

La producción y puesta en circulación controladas es tanto una respuesta a la concentración -también porque la mayoría de las librerías tiende a priorizar la promoción de los libros de los grandes grupos y descuidar los de las editoriales autogestionadas-, como una medida para reducir costos: "Hacemos todo el trabajo nosotros (selección, corrección, maqueta, diseño de tapa, trato con imprenta, prensa como se puede) así que no tenemos sueldos ni honorarios que pagar, por ahora todo va a la imprenta" (Porrúa 75-76), afirman los editores de Iván Rosado de Rosario. Lo mismo que los editores de Neutrinos, originalmente de La Paz, Entre Ríos, y ahora también de Rosario:

Los libritos son maquetados, impresos y abrochados o cosidos en casa. Nos gusta esa relación directa con los libros, estar en contacto permanente, participar en todo el proceso de elaboración, de principio a fin. Nuestras publicaciones son caseras, pequeñas, de ahí viene un poco el nombre de la editorial, los neutrinos, por definición, son partículas subatómicas que tienen la capacidad de atravesar la materia.

(Porrúa 78)

Y Julián Bejarano, por su parte, que "La idea era no dejar librado al azar en toda la cadena de producción a gente de afuera que no pusiera el corazón, ganas, onda y pasión en su trabajo” (Porrúa 80). Mientras, Ediciones Inubicalistas, de Valparaíso, se presenta a sí misma "como una manera de superar la precariedad de recursos y ejercitar el trabajo colectivo” (González 98).

Como deja entrever Daniela Szpilbarg a partir del caso de Funesiana, otra editorial artesanal argentina, y ya hemos visto con Schierloh y Barba de abejas, el hecho de que la industria editorial nacional se viera sometida a un proceso de concentración se va a constituir, paradójicamente, en un impulso a la edición autogestionada y artesanal, además, con un valor simbólico agregado -a la vez estético y político- que no existe en la edición más comercial: 
['Funes' Oliveira] cuenta que "no poder publicar me llevó a encuadernar mi primer libro de cuentos". Y el hecho de que estuviera cosido por su propio autor, lo dotaba de un poder muy particular, al mismo tiempo que marcaba una ruptura en el modelo del autor, artista sacralizado, alejado de la producción material, de la fuerza de trabajo, de la mercancía. Uno de los puntos de contacto entre estas editoriales "autogestionadas", surge también del hecho de intervenir en la producción total del libro, desde la concepción de la idea, hasta ver la misma materializada en un objeto con sus marcas propias.

(“Editoriales artesanales...” 14)

Resulta conveniente destacar, no obstante, que esta posibilidad de expandir los dominios de la producción artesanal y autogestionada existe gracias a los desarrollos tecnológicos recientes y a una voluntad autoconsciente de tener bajo control los medios y la lógica de producción. Al respecto, los editores de Perro de puerto, también de Valparaíso, sostienen que "el acceso tecnológico a impresoras y computadores permite llevar a cabo el proceso completo de producción en la casa, o generar tiradas según necesidad, que se van afinando con el tiempo" (“Ediciones Perro...” 133).

Esta serie de elementos estructurales - precariedad relativa, carácter artesanal, doméstico y autogestión- posee, por otro lado, una implicancia en la materialidad de los soportes que, a su vez, se traslada a las configuraciones textuales. Se trata de que, bajo estas condiciones de producción, la literatura que va a predominar es, por lo pronto, la de menor extensión, ante todo, la poesía o, por contigüidad práctica, cualquier forma que la consagre como paradigma y la emule. En referencia al caso argentino, Ana Mazzoni y Damián Selci han observado que

La crisis económica que prácticamente destruyó la industria editorial nacional es también un principio estructurante de la literatura actual. Es que la condición de hecho de la publicación se vuelve condición de derecho de la escritura como tal: si alguien quiere ser leído, que escriba poemas; y si insiste en la narrativa, entonces que sea breve (como un poema). Por supuesto, no estamos diciendo que este principio suceda o haya sucedido en algún caso empírico particular, puesto que desde que existe, contamina toda la producción literaria. Toda la literatura actual está organizada en torno a la escasez de recursos, aun cuando se positivice esta carencia -aun cuando muchos amen sinceramente la poesía y detesten la narrativa, aún ellos escriben poesía porque en cierto modo no pueden hacer otra cosa. No hay elección: o poesía, o algo que económicamente se le parezca. Esto nos lleva a pensar que, al menos desde el punto de vista económico, la literatura de que tratamos es únicamente poesía. Ella se vuelve entonces una especie de obligación, una opción alienante: o poesía o nada. (264)

Voy a detenerme en la poesía en el cuarto apartado de este capítulo, lo que me interesa destacar a partir de esta cita es que las condiciones bajo las que se produce la literatura, si se les da crédito a Mazzoni y Selci, no serían irrelevantes para la escritura o para la literatura en sí misma y, por lo tanto, merecen mayor 
atención de lo que usualmente se cree en los estudios literarios. Esto implica también que las condiciones locales, en un territorio como el latinoamericano, darían lugar a formas textuales que no serían hallables de la misma manera en el circuito mundial. Quiero decir, la precariedad -conceptualizada como un recurso positivo ("creemos en la escasez como sistema de producción" -editorial Economías de guerra-) o no, no importa- sería un factor condicionante de la literatura, es decir, que la estaría obligando a adquirir matices particulares y que, por lo tanto, el trabajo de indagar la literatura latinoamericana no consistiría en abordar la que tematiza o ilustra aspectos de su paisaje natural o cultural, sino, mucho antes, la que se encuentra marcada por condiciones de producción locales. ${ }^{6}$

Esta posibilidad de comprimir la cadena productiva - no solo porque ciertos mediadores, como los scouts, no resultan necesarios o son prescindibles, sino también porque quien escribe el texto puede coincidir con la persona que entrega el libro al consumidor- obliga a introducir algunas reflexiones sobre el carácter "profesional" que definiría al sistema productivo de la industria transnacional. A comienzos de los años 00, Adriana Astutti y Sandra Contreras recordaron los inicios en 1991 de su editorial, Beatriz Viterbo, en los siguientes términos:

No hicimos estudios previos de marketing (ni posteriores); no buscamos contactos con agentes literarios ni planteamos estrategias de lanzamiento (y a decir verdad nos cuesta pensar la posibilidad de hacerlo alguna vez). Tampoco quisimos trazar de antemano una línea editorial, pero sabíamos perfectamente qué cosas no íbamos a publicar. [...] Ciertamente no respondimos a una imagen de editor profesional. (772)

Se extrae de estas palabras que las editoras, abierta y conscientemente, decidieron fundar su proyecto en una política editorial, un modo de gestión, no "profesional" o, más bien, diferenciado del que se manifiesta a priori como “profesional”. Procuraron, por lo pronto, no medir riesgos ni regular la publicación en función de previsiones de mercado, prescindieron, además, de los servicios de ese mediador ineludible para la literatura mundial: el agente

6 El procedimiento de vincular un texto a una determinada configuración geocultural con base en aspectos temáticos o de contenido conduciría a pensar que Under the Volcano (1947), de Malcolm Lowry, es una novela mexicana, o que el primer cuento de Juan José Arreola, “Gunter Stapenhorst” (1946), es un relato alemán, lo cual puede resultar completamente legítimo, pero no es mi opción. No creo, por otra parte, que el origen de una escritora o de un escritor permita adscribir su producción a un orden nacional o regional, pero sí que las condiciones materiales de producción dan lugar a desarrollos escriturarios diferenciados y diferenciables. 
literario. ${ }^{7}$ La generalización de estos factores, sumado a la relativa "ineficiencia" y a que las competencias profesionales específicas que van de la redacción de contenido a la distribución y venta, pasando por la corrección, diseño y diagramación del libro, pueden -y suelen- ser asumidas por un único actor o muy pocos, permite introducir la idea de que los sistemas productivos de las literatura locales no son "profesionales". Esta maniobra retórica -porque en realidad sí lo serían si los criterios para medir el profesionalismo no respondieran a principios economicistas- sería útil para demarcar los sistemas productivos locales como disidentes, es decir, deliberadamente opuestos a la lógica que impulsa la industria cultural transnacional. Como ya propuse, los sistemas productivos de las literaturas locales suelen presentarse como "artesanales", no tanto -aunque este factor se encuentre en efecto bastante extendido- porque los libros se produzcan manualmente, como en el caso de Barba de abejas o Juan Malasuerte, de México, o en talleres domésticos, como en el caso de Germinal de Costa Rica, sino, antes, porque las actividades materiales involucradas en el proceso de elaboración no se realizan de la misma manera que en la producción en serie o industrial, donde la división del trabajo determina una pérdida de control sobre el objeto elaborado. Aunque los libros de las literaturas locales pasen por una imprenta de la industria gráfica convencional, suelen no perder un cierto carácter individual que se expresa, por ejemplo, en la numeración de los ejemplares o en la cuidadosa selección de imágenes de tapa realizadas -como en el caso de la editorial Mansalva- ad hoc por artistas vinculados al proyecto. Así, para resumir, el carácter "artesanal" de los sistemas locales estaría definido ante todo por una oposición deliberada al sistema "profesional" y "eficiente" de la industria transnacional, los objetos producidos serían, en este sentido, portadores de marcas distintivas al manifestarse como libros más o menos únicos, es decir, nunca comparables con los producidos en serie para el consumo más masivo. ${ }^{8}$

7 Para mayores precisiones acerca de la función de los agentes en la producción de literatura latinoamericana mundial, remito, nuevamente, a Locane "La mediación...".

8 Mi definición de modo de producción "artesanal", como "alternativo" -y, con esto, no menos desarrollado- al que postula la industria editorial transnacional y característico de las literaturas locales, coincide con el que propone Cecilia Palmeiro en su estudio sobre Eloísa Cartonera y Belleza y felicidad, esto es, que no necesariamente hay que pensarlo en relación antagónica con las diferentes innovaciones de las tecnologías gráficas. Como antecedente inmediato a los proyectos más recientes, Palmeiro remite, en los siguientes términos, a la poesía marginal brasilera de los años 60: "Que la poesía marginal utilizara la técnica de manera artesanal no significaba una negación del desarrollo tecnológico, pero sí un cuestionamiento a las relaciones de producción que éste traía aparejadas en las condiciones vigentes de su desarrollo y bajo el paraguas de la idea de progreso. El carácter artesanal del trabajo (es el mismo autor quien escribe, imprime y vende) suponía otra relación entre el sujeto y el objeto producido, así como 
Otro aspecto que permite caracterizar al sistema productivo que acá interesa y que lo distingue- tiene que ver con la cobertura territorial, con el orden simbólico-cultural donde pretenden situarse las editoriales y también, ciertamente, con los alcances de distribución, es decir, en términos generales, con la dialéctica que los diferentes nodos de producción entablan con el espacio geográfico y social. Si el sistema productivo de la literatura mundial busca, por naturaleza, el desborde de fronteras y la circulación transnacional, las editoriales del circuito alternativo suelen hacer de las limitaciones en lo que refiere a posibilidades de distribución, circulación y llegada un valor y una marca identitaria. Junto a esta inscripción estratégica en contextos específicos -que también se manifiesta en la publicación de escrituras decididamente locales-, se observa, sin embargo, un uso recurrente y activo de internet y las redes sociales como medio para generar visibilidad, presencia en la red alternativa y cierto desborde, al menos conceptual, del ámbito más localizado.

Algunas editoriales van a seguir priorizando el marco nacional como recurso para delimitar su catálogo y -frente a la industria transnacional- su rasgo distintivo: "Índole es una editorial independiente. Nuestra apuesta editorial está, por hoy, centrada en la literatura nacional”, se lee en una de las plataformas de la editorial salvadoreña Índole; y en una caracterización de "editoriales independientes” ofrecida por la editorial chilena Das Kapital que

Los proyectos editoriales emergentes de este tipo presentan innovadoras fórmulas en cuanto a gestión editorial, distribución, producción de libros y desarrollo de autores dedicándose en su gran mayoría a movilizar a los autores nacionales inéditos y a través de sus trayectorias impulsar una nueva dinámica de editorial/autor. Este modelo se ha replicado a través del mundo en contraposición a los grandes conglomerados, aumentando de esta manera tanto la aparición de editoriales como el posicionamiento de nuevos autores tanto dentro del circuito literario como dentro del circuito comercial, entregando un registro único de lo que está sucediendo dentro del campo de la literatura chilena, autores quienes por su activa participación dentro de la escena literaria son parte del circuito vivo y poseen en muchos casos trayectorias y propuestas literarias estéticas que nutren la literatura. En cuanto a los editores, son actores que plantean y proponen al público panoramas, análisis del estado de la industria y propuestas diferentes a las ya tradicionales editoriales

una crítica a la división entre trabajo intelectual y manual” (96). Para acentuar más aún el concepto, se puede retomar el manifiesto de Glauco Matosso quien señalaba que los poetas marginales "são desconhecidos do grande público, e produzem e vinculam suas obras por conta própria, com recursos ora precários, ora artesanais, ora técnicos, mas sempre fora do mercado editorial" (20). En breve, los pilares sobre los que se funda la edición artesanal serían la autogestión, la compresión de la cadena de mediaciones y, al margen de un mayor o menor uso de recursos técnicos, un distanciamiento deliberado de la lógica y el circuito de la industria editorial establecida. 
instaladas en el mercado. De ahí su relevancia y aporte al desarrollo de la literatura nacional como a la industria del libro, ya que es solo a través de ellos por quienes podemos presentar las distintas narrativas, poéticas y líneas editoriales que se están experimentando dentro del país.

(“Das Kapital” 81-82)

Si en esta caracterización lo que aparece puesto de relieve -como medida compensatoria al siempre denunciado desinterés de las transnacionales- es la función de registrar y favorecer la dinámica de la literatura del presente a escala nacional, en general, las editoriales que optan por autoasignarse una identidad nacional lo hacen como revisión crítica y analítica antes que confirmatoria. Pretenden, antes que exaltar la matriz nacional heredada, el archivo de tópicos obligado, estimular reflexiones, debates y replanteos hacia el interior de ella. Así, Ediciones de a Poco, sin dejar de inscribirse en la tradición literaria, social, política- de República Dominicana, introduce un matiz crítico en relación con ella: se trata, según informa el sitio web, de "Una propuesta editorial dedicada a la literatura y a los libros visuales que busca publicar obras originales que cuestionen e inviten a comprender la realidad contemporánea dominicana y caribeña”. De un modo similar -que enfatiza el presente y un anclaje crítico al contexto nacional-, la editorial La calabaza del diablo afirma que "La edición pasa por la construcción de un lector, de una poesía y narrativa que tenga que ver con la realidad del chileno común. El ciudadano de a pie. Individuos que estén preocupados de la historia reciente de este país" (“La calabaza del diablo" 29).

Otros pequeños sellos/proyectos, no obstante, han optado por remarcar su incapacidad/desinterés por reforzar -aunque sea críticamente- la matriz de producción y lectura en clave nacional. Son propuestas que resignifican como valor la especificidad microterritorial, de manera que rechazan tanto la desterritorialización que distingue al circuito productivo transnacional como el marco de la tradición nacional para autoasignarse, así, un matiz identitario y una base operativa, en un sentido riguroso, locales. Se posicionan como una afronta tanto a los centralismos internos como a los pretendidos descentramientos externos. Y, dado el caso, desde ese lugar geográfico y de enunciación, que es tanto un nicho ínfimo de mercado como un resguardo estratégico de la diferencia cultural, van a establecer enlaces, diálogos y redes de gestión y afinidad alternativas. En el sitio web de Neutrinos, por ejemplo, se hace explícito cuál fue en sus comienzos -porque ahora tiene sede en Rosario- su horizonte de acción:

El proyecto se inició en 2012 en La Paz, un pueblo sin librerías al noroeste de Entre Ríos, con la intención de promover la circulación y la lectura de poesía contemporánea a nivel local. Así nació la colección de plaquetas, que se mantiene hasta hoy, conformada por más de 20 
títulos de autores argentinos, latinoamericanos y europeos. Por su económico precio de venta y su pequeño tamaño, las plaquetas permiten una distribución y un intercambio fluido e informal, ideales para regalar, prestar y perder.

Como se advierte, también en este sentido, las condiciones locales determinan formatos, estrategias y políticas editoriales. Pero esas condiciones, que en principio, según la perspectiva dominante, no ofrecerían más que limitaciones, pueden ser resemantizadas en términos positivos, como estímulo al despliegue de creatividad en busca de soluciones que siempre van a ser alternativas al modelo convencional: "Somos del puerto de San Antonio" -informa el sitio de Economías de guerra- "y creemos en la escasez como sistema de producción, en el trabajo editorial como estrategia crítica y textual y un modo de habitar el territorio". De este modo, en este nivel se articulan, como agenda programática, una política de revaloración de los márgenes geográficos y culturales con una que le restituye importancia al trabajo no alienado, manual y creativo. Dicen los editores de Perro de puerto -que publica libros abrochados y sin ISBN, y que se presenta como "una microeditorial territorial que busca rescatar voces flotantes en la ciudad de Valparaíso"- que "mejor aún si existe la doble consciencia de edición artesanal y significado político, especialmente si es con vínculo territorial, creando un imaginario para su localidad y olvidando la tentación del centro" ("Perro de puerto" 132-133). Esta operación decididamente consciente en y con lo local no debe leerse, sin embargo, como una exaltación irreflexiva de atributos singulares esencializados, sino como una intervención estratégica en un escenario histórico dominado por el proyecto de expansión liberal, por la concentración de la industria editorial y por una tendencia general al aplanamiento de las formas literarias en una clave que se resuelve, principalmente, dentro de los límites de la novela decimonónica siempre reinventada como novedad. El énfasis en las microlocalidades alternativas, desmarcadas incluso de los centros de producción cultural a nivel nacional, no descarta, por eso mismo, enlaces estratégicos que, en conformidad con estudios recientes, bien pueden ser caracterizados como translocales, ${ }^{9}$ pues, estos proyectos, como ilustra la cita que sigue, estarían diseñando circuitos alternativos a los de la industria convencional; filamentos, desde ya siempre débiles, pero convencidos, entre nodos de gestión dispersos por una geografía desbordada: "VOX es un proyecto cultural que se desarrolló en la ciudad de Bahía Blanca entre 1994 y 2015 y que ha establecido acciones y vínculos con artistas,

9 Una aproximación orgánica desde diferentes perspectivas se encuentra en el volumen colectivo editado por Ulrike Freitag y Achim von Oppen. Véase también Appadurai y Greiner/ Sakdapolrak, entre otros. 
escritores, docentes, gestores, editores y diversos proyectos culturales de Argentina, Latinoamérica y Europa” (sitio web proyecto VOX).

El arraigo local de las editoriales, y su uso estratégico para la elaboración de subjetividades y comunidades de lectura críticas, adquiere, así, una importancia capital para el sistema de las literaturas locales. Cada núcleo de operaciones, con plena autonomía para diseñar un catálogo y un proyecto editorial, y permitir, por lo tanto, que la escritura arrastre marcas distintivas, funcionaría tanto como garantía para un efectivo descentramiento de la producción de bienes simbólicos así como a modo de un potencial engranaje de una maquinaria translocal desjerarquizada pero también susceptible de ser abordada de manera orgánica. Los diferentes sistemas productivos de las literaturas locales, ubicados en la espacialidad concreta de América Latina, configurarían, de esta manera, una trama reticular que la mirada analítica puede -si se lo propone- reconstruir como alternativa -descentrada, siempre creativa y respetuosa de las especificidades- al sistema centrado en Barcelona.

En este sentido, anota Gladys González que, para las editoriales independientes de América Latina, "Es importantísimo el rescate de nuevas lecturas y ampliar la mirada editorial dando acceso a la publicación de obras de escritores que no sean parte de una élite construida sobre puntos geográficos o deformaciones profesionales de espectáculo" (5). Para esto, justamente, para desafiar la jerarquía del sistema de la literatura latinoamericana mundial y resguardar la diversidad de escrituras, ya sea de formas como de nombres de autor, resulta decisivo un corrimiento de la mirada hacia las configuraciones locales y sus dinámicas productivas aunque estas no cuenten con los favores de la economía del prestigio global.

En resumen, los sistemas productivos de las literaturas locales latinoamericanas, concebidas como las que no se proyectan más allá de dominios geoculturales específicos o que muestran resistencia a reinscripciones contextuales, se caracterizan por una serie de elementos que, por razones vinculadas a la lógica de gestión, a las condiciones materiales de producción particulares y porque tienden a cerrarse sobre sí mismos al desmarcarse del circuito comercial, permite distinguirlos del sistema productivo concentrado sobre el que se funda en la actualidad la literatura mundial. Al comprimir la cadena productiva y liberarse de la mediación de los representantes más característicos del polo heterónomo y puesto que no dependen de mayores recursos económicos para su funcionamiento, estos sistemas constituirían un resguardo de la autonomía (crítica) de la literatura y funcionarían como dinamizadores de campos literarios aún, y fundamentalmente, organizados en torno a un valor tan literario como político, en el sentido que lo pensaría 
Jacques Rancière. ${ }^{10}$ Las características que los definen estarían dadas por modos de producción condicionados por la escasez relativa de recursos, lo que, en concreto, se traduciría en libros breves, más o menos “anómalos”, en casos sin ISBN, ${ }^{11}$ y tiradas de pocos ejemplares elaborados cuidadosamente a mano o en talleres domésticos que, más tarde, entran en circulación a través de canales restringidos o alternativos como ferias autogestionadas. Todo el proceso de producción, desde la elaboración de contenido hasta la llegada a los consumidores del objeto acabado, estaría, además, en manos de contados actores que, al seguir de cerca o incluso concretar personalmente las diferentes etapas, asumirían numerosos roles profesionales que en la industria editorial convencional se distribuyen entre diferentes técnicos con competencias específicas. Por otro lado, destaca en estos sistemas una resignificación y revaloración de los microdominios locales más o menos apartados de los centros mundiales y, en casos también regionales, de gestión. Se constituyen, así, en plataformas de expresión que garantizan la diversidad cultural y también de las formas literarias no asimilables por el sistema comercial. Velan -se podría decir- por la sobrevivencia de las literaturas menores ya no en el ecosistema nacional sino en el mundial. En su conjunto, adquieren -no necesariamente porque existan enlaces comprobables empíricamente, sino antes porque una determinada mirada analítica así lo dispondría- la apariencia de una red descentrada en la que cada nodo productivo disfruta de total autonomía y, sin embargo, es irremplazable. En tanto red o sistema de sistemas, la matriz productiva de las literaturas locales representaría -como voy a tratar de demostrar en el próximo apartado- una garantía para una auténtica bibliodiversidad y, eventualmente, para una literatura mundial disidente, no diseñada en función de necesidades comerciales de actores centralizados en la metrópoli.

10 La autonomía que estoy tratando de conceptualizar -y que probablemente coincide con algunas nociones implícitas en Bourdieu- no es, desde luego, la del artepurismo decimonónico, sino una que procuraría hacer de las expresiones estéticas un territorio reservado para la libertad crítica y el disenso. Se trata, de alguna manera, de una autonomía no reñida con los postulados de ciertas vanguardias históricas y neovanguardias.

11 La ausencia de registro ISBN (International Standard Book Number) es en muchos casos un gesto deliberado de política editorial. Por medio de esta estrategia, el artefacto en cuestión sería sustraído del circuito comercial. Para un estudio en profundidad que, además, ofrece un catálogo de mil seiscientas publicaciones actuales de todo el mundo sin ISBN, véase el volumen editado por Cella et alii. 